\title{
Lessons Learned about Building an ASSERTive Community
}

\section{Dr. Donna C. Llewellyn, Boise State University}

Donna Crystal Llewellyn received her BA (major in Mathematics and minor in Economics) with High Honors from Swarthmore College in 1980. She went on to earn an MS in Operations Research from Stanford University in 1981 and a Ph.D. in Operations Research from Cornell University in 1984. After 30 years at Georgia Tech in a variety of roles, Donna became the Executive Director of the new Institute for STEM and Diversity Initiatives at Boise State University in January 2015. Donna's current interests center around education issues in general, and in particular on increasing access and success of those traditionally under-represented and/or under-served in STEM higher education.

\section{Prof. William L. Hughes, Boise State University}

Professor William L. Hughes is the Director of the Micron School of Materials Science \& Engineering at Boise State University. He also serves as the Director of the Nucleic Acid Memory Institute, where his research team reads and writes information into DNA for archival storage applications. Finally he is a faculty fellow of the College of Innovation + Design, which he cofounded at Boise State. Professor Hughes received his B.S. and Ph.D. in Materials Science \& Engineering from Virginia Tech and Georgia Tech. Prior to his current appointments, he served as a Center for the Advancement of Scholarship on Engineering Education, via the National Academy of Engineering, as well as an Assistant Professor of Materials Engineering at the California Polytechnic State University.

\section{Megan F. Gambs, Boise State University}

Megan Gambs is the Project Manager for the Institute for STEM \& Diversity Initiatives at Boise State University. She works towards improving access and success for those historically marginalized in STEM through programs with and opportunities for various stakeholder groups (e.g. students, teachers, and faculty). Her experience serving as a middle school science teacher in Nampa, Idaho, inform her work at Boise State. 


\title{
Lessons Learned about Building an ASSERTive Community
}

\begin{abstract}
One of our observations in this lessons learned paper is that there is underwhelming faculty development related to scholarship other than on how to submit and sometimes how to write proposals. This de facto service model misses everything outside of the proposal-writing process; which is the least important, but is often the most celebrated, rewarded, and supported phase. Inspired by national Centers for Teaching \& Learning, and modeled after the emerging Communities of Transformation literature, we are piloting a Center for Transformative Research at Boise State University. The vision of our Center is to build and sustain an ASSERTive community -- for Aligning Stakeholders and Structures to Enable Research Transformation (ASSERT). Faculty members from across campus were recruited to participate as fellows to explore what it means to be a scholar and how to move a bold and transformative idea forward. To minimize the energy to apply, the application process included an Instagram post, Twitter response, and/or haiku. Fifteen faculty were selected for the cohort of fellows. To ensure university-wide accountability, a memorandum of understanding was signed by each fellow, as well as their Provost, Vice President for Research \& Economic Development, College or School Dean, and Department Chair. Once signed, each fellow was asked to complete a survey and participate in an individual structured interview with the PI and co-PI. These allowed us to determine the specific needs of each fellow, providing validation or perhaps challenging our a priori observations of risk inhibitors at Boise State that prevent germination of bold ideas. By studying the fellows, we were able to look at what may inhibit them from taking risks - personal attributes and beliefs, and structural and cultural issues within their academic units, the university, and in their academic fields. Based on the survey results and individual structured interviews, programming was developed and tailored to the needs of the fellows. An off-campus retreat was held. In addition to the off-campus retreat, on-campus workshops were custom-made for the fellows and included: (a) how to germinate transformative ideas by no longer seeing ideas as precious; (b) how to become an effective collaborator by adapting the Toolbox Project; (c) how to move ideas forward by drawing on the game "Chutes \& Ladders" where the chutes represent common obstacles and the ladders are shortcuts; (d) how to manage time at work, and in life; and (e) how to classify, understand, and know when and how to implement intentional versus emergent research strategies. As a culminating activity, the faculty then pitched their ideas to university and community leadership. In conjunction with this pitch event, an advocate was assigned to each fellow to help connect their ideas to future resources. From our motivation to our faculty application to our custom learning community, lessons learned will be shared via a lightning talk.
\end{abstract}

\section{Background and Motivation}

In a proposal to the National Science Foundation (NSF; award no. 1745944), we laid out our plan to adopt practices from the instructional realm-a core area of the university where there is a well-accepted realization of an elevated need for professional development, institutional, cultural, and structural transformation-into the scholarship development realm. Most campuses have a Center for Teaching and Learning that provides a portfolio of support programs for faculty as they develop their teaching identity and grow into effective educators. Initially, they 
began with individual faculty experts serving as consultants to other faculty to help them improve their teaching skills. Then, in response to student empowerment movements and faculty grassroots efforts, American campuses built the infrastructure to improve student learning. In addition, in the current times, these units have recognized their role in institutional transformation and strategic alignment around the teaching and learning mission of the university [1].

Historically, faculty professional development at US universities centered on academic scholarship_originating with the faculty sabbatical at Harvard University and leading to support for individual faculty researchers through research administrative units [1]. Today, most campuses have a Vice President for Research whose office supports grant writing, proposal development, team formation, and communication outreach about funding opportunities [2]. According to the National Organization of Research Development Professionals, "Research Development professionals serve as 'rainmakers' who catalyze and facilitate team science in response to the external funding landscape." From our perspective, this statement misses the fact that the rain is usually a consequence of the environment. Further, due to the financial focus of where they work, many Research Development professionals often lack the mission or experience to support psychological safety, design thinking, and Communities of Transformation (CoTs) [3]. As a result, their offices are designed to be responsive rather than developmental; they help faculty and teams respond to calls for funding rather than provide the professional development necessary for a team to be ready for that call or to help them define the transformative scholarship that will go into the call. Indeed, on most campuses, there is no faculty development related to research other than on how to submit and sometimes how to write a proposal. This service structure is missing everything before and after the proposal-writing phase and excludes faculty that do not seek or require external funding sources. The academy needs a new model for faculty professional development around research.

Because the richest place to find transformative research is often in the interstitial space between well-defined areas of inquiries, the ability to formulate such questions often requires a team of researchers, each with their respective disciplinary lens, expertise, and epistemology. However, it is not enough for researchers to simply come together naively, but rather it requires a collaborative endeavor to negotiate the unknown territory of a new line of investigation and to craft a research question that can be explored. Realistically, most academics do not possess the agency or capacity to germinate transformative ideas nor do they work in a psychologically safe environment that supports true intellectual risk taking.

We are piloting the Center for Transformative Research at Boise State University to tackle these issues. The current grant funds the development and support of a faculty learning community cohort of 10-15 faculty each year. The goal of this work is to help the cohort germinate and move their bold ideas forward within Boise State. Upon success, we envision the Center to grow to include activities parallel to those often found in Centers for Teaching and Learning, ranging from faculty consultancy and professional development to institutional change. Below we discuss our experiences with our second of three funded cohorts funded by the National Science Foundation. 


\section{The Fellowship Year}

\section{RECRUITMENT PHILOSOPHY AND PROCESS}

We recruited faculty participants from across campus through emails directed to the deans, chairs, and directors of all academic units. We had a goal of recruiting a diverse set of participantsalong dimensions of personal identity, rank, and discipline - of research active and research aspiring faculty, in order to foster a transdisciplinary learning community.

To minimize the activation barrier to engage, the application process included submitting responses in the form of an Instagram post, Twitter tweet, or haiku to each of three questions: (1) Why do you want to participate, (2) What is one thing you will bring [to the cohort], and (3) What is one thing you wish to learn [from the cohort]? For example one fellow responded to the question - Why do you want to participate - with an Instagram post that included an image of a scientist falling to their death in a grain silo with the post, "I study agricultural health and I know silos are deadly; they are deadly in research too. I want to change how we feed the world and I know we can't do that by each nibbling at our own edge of the problem. I want a plan for how to think bigger. \#DiscardTheSilos." When the same fellow was then asked - What is one thing you will bring - they responded with a twitter feed, "A stack of unanswered questions. A burning desire for change. Health science and epidemiologic expertise. \#ASeatAtTheTable \#PutMeInCoach." Finally, when asked - What is one thing you wish to learn - the same fellow wrote a vulnerable haiku: "I know my limits: Iterative; linear. How can I expand?" During ASSERT, the fellow expanded their research in brave new ways; securing a major federal grant.

These three questions and the unorthodox format of the requested responses gave us a view into the creativity and flexibility of the applicants along with a sense of what they really wanted to both give to and take from the experience. And, not to be overlooked, the response format made it fun to read the applications!

In addition, the applicants were asked to indicate an agreement to meet on certain dates during the fall semester for the first term of the learning community - they had two choices. In addition, applicants agreed to secure dates for the fall off-campus retreat.

We used availability of the applicants for the faculty learning community dates along with their responses to the three questions to form a cohort of faculty from across campus that met our goals of diversity and genuine interest in full engagement. Fifteen faculty, called ASSERT Fellows, were selected to engage in the yearlong ASSERTive community-for Aligning Stakeholders and Structures to Enable Research Transformation (ASSERT). The goal of having a diverse set of participants was realized with a cohort consisting of six women and nine men, at all ranks (i.e. Assistant, Associate, and Full Professors), and from multiple academic units on campus (Biology; Community and Environmental Health; Computer Science; Curriculum, Instruction, and Foundational Studies; Electrical and Computer Engineering; English; Materials Science and Engineering; Mechanical and Biomedical Engineering; Nursing; Philosophy; Physics; Public Policy and Administration).

To ensure university-wide accountability, a memorandum of understanding (MOU) was signed by each fellow, as well as the University Provost, Vice President for Research \& Economic 
Development, the appropriate College or School Dean, and Department Chair. The MOU outlined that participation in the ASSERT fellowship was to be considered equivalent to other forms of scholarship, including but not limited to an external proposal, peer-reviewed publication, invited oral or poster presentation, and patent. As such, participation was to be included in the annual evaluation of the fellows, including a letter of support from the PI and coPI, if requested, outlining the contributions from all involved. By signing the MOU document, all parties agreed to uphold this understanding.

Once the MOU was signed, each fellow was also asked to sign a consent form since due to the funding arrangement, they were also serving as a research participant in an IRB controlled study. Then, each fellow was asked to complete an online survey. The survey included various questions that sought to gauge perceptions of tenure and promotion policies and preparedness to undertake acts of scholarship via Likert scale responses.

To quantify the baseline grant activity for each fellow, the Office of Sponsored Programs at Boise State University provided the PI and co-PI the number and type of proposals submitted, awarded, and pending for the calendar year prior to their participation in this project. In addition, the fellows were asked to provide their NSF conflict of interest forms and their curriculum vitae to help the PI and co-PI evaluate the richness of their professional network and contributions, respectively.

Following the survey, an individual structured interview with the PI and co-PI occurred to determine the specific needs of each ASSERT Fellow, providing validation or perhaps challenging our a priori observations of risk inhibitors at Boise State that prevent germinating bold ideas. By studying the ASSERT Fellows, we were able to look at what may inhibit them from taking risks-personal attributes and beliefs, and the structural and cultural barriers within their academic unit, the university, and in their academic field.

During our individual structured interviews with the ASSERT Fellows, we gained a sense that many of the faculty felt isolated in the way that they were approaching their scholarship, and that there was a lack of clarity across campus about what kinds of scholarship were truly valued. This gained understanding helped to inform the programming for the fellowship year; as well as build empathy among the participants when confronted with the reality of their peers across campus.

\section{RETREAT AND WORKSHOPS}

Based on the survey results, individual structured interviews, and baseline performance metrics outlined above, a fall retreat was held at the McCall Outdoor Science School in the Ponderosa State park in McCall, Idaho. By convening off-campus and away from home, we cultivated a greater sense of community. Programming was able to be uninterrupted and intentional. During the retreat, the fellows: (1) participated in a question and answer session about the arc of scholarship at Boise State ; (2) captured their personal and professional values in support of making more informed decisions; (3) highlighted their preferences as both citizens and scholars; (4) participated in a mindfulness activity to help address difficult challenges by engaging with nature at multiple scales [4]; (5) digested key passages of Ernest Boyer's Scholarship Reconsidered: Priorities of the Professoriate [5]; (6) designed a product using human-centered 
approaches; (7) interpreted photographs as metaphors for different types of scholarship; and (8) gave two-minute lightning talks that were specific to their big ideas.

In support of elevating the conversation about what it means to be a scholar today, the PI and coPI read Ernest Boyer's Scholarship Reconsidered: Priorities of the Professoriate [5] alongside the ASSERT Fellows, as well as independently with the Interim Provost and Dean's Council at Boise State. In doing so, positive pressure was simultaneously applied to the bottom and the top of the organization in service of developing a more ASSERTive campus.

Beyond the off-campus retreat, ten on-campus workshops and other coaching opportunities were intentionally designed for the ASSERT Fellows. Programming during these experiences included: (1) how to germinate transformative ideas by no longer seeing ideas as precious; (2) how to become an effective collaborator by adapting the Toolbox Project for the specific needs of each Fellow [6]; (3) how to move ideas forward at Boise State by drawing on the game "Chutes \& Ladders" where the chutes represent common obstacles and the ladders are shortcuts; (4) how to manage time at work, and in life, by providing case studies from the PI and co-PI, and by introducing fellows to a related research study underway at Boise State University called the TAWKS (Time Allocation Workload Knowledge Study) Project [7]; (5) opportunities to listen and learn about the research progress and challenges of the fellows as a faculty learning community; (6) how to classify, understand, and know when and how to implement intentional versus emergent research strategies; (7) peer review of white papers in a faculty learning community; (8) guest appearance from Gary Machlis, a nationally recognized professor at Clemson University, who was able to articulate the challenges facing academia and our nation today; (9) multiple open-door opportunities to talk informally with the PI and co-PI; and (10) multiple celebrations over non-federally funded beers and cheers.

Many ASSERT Fellows took advantage of the open-door opportunities with the PI and co-PI. For example, over the course of the year, the PI and co-PI worked with a Fellow to embrace their strengths while working on various personal and professional challenges. The end result is that the faculty member received an NIH K Award, published a highly impactful article, and most importantly gained confidence that they can both germinate bold ideas, as well as move them forward. At the conclusion of the fellowship year, another ASSERT Fellow acknowledged the impact and importance of participating in this community. This fellow stated that, "If it weren't for this program, I would now be on the job market." A third fellow remarked, "The chance to view faculty life through the eyes of the rest of the community of ASSERT Fellows has been invaluable. The widely varying perspectives on things as a result of peoples' career stages (tenure vs. pre-tenure for example) and disciplines have allowed me to better understand where I am and where I am going."

\section{PITCH EVENT}

To offer ASSERT Fellows the opportunity and external support to move their bold ideas forward and to showcase ASSERT, the PI and co-PI, in collaboration with their units and the Division of Research \&Economic Development, hosted the pitch event. With the support of University Advancement, this experience brought together ASSERT Fellows, university administrators, and community, government, and industry leaders to celebrate and share transformational research ideas. 
The pitch event was set in one of the most sought-after spaces in the university, with nearly 360degree views of Boise and its foothills. The space is often reserved for University patrons and prestigious events. By situating the event in this space, we underscored the importance of ASSERT on campus and in our community. At the University's premier gathering space, the faculty cohort, along with university administration and leadership (e.g. provost, vice presidents, deans, chairs), and community influencers gathered for breakfast and networking. After introductions by the Interim Vice President of Research \& Economic Development, the PI and co-PI framed the experience, offering a brief primer on ASSERT and asked the audience to provide constructive and supportive feedback to help ASSERT Fellows move their ideas forward. Each fellow was allotted three minutes to share their transformational research idea with the use of only one visually impactful image. Audience questions and applause were held until the end when all fifteen fellows took the stage to field audience questions and comments.

Preparation for the pitch event was embedded in all ASSERT programming. From scholarship speed dating - where fellows shared their research interests with one another in a fast-paced and structured environment - to the study of Boyer's Scholarship Reconsidered [5], fellows built the skills to cultivate their bold research ideas and the confidence to share their ideas with a diverse and influential audience. Prior to the pitch event, fellows created and revised NSF-style whitepapers, which described their research and underscored the societal need for their research. In addition, ASSERT Fellows rehearsed and revised their three-minute presentation to ensure that each presented their best at the pitch. Individualized constructive feedback was provided to fellows for both their pitches and whitepapers.

In collaboration with the Division of Research \& Economic Development and University Advancement, we identified University leadership and community influencers who were situated in both space and place to serve as advocates for ASSERT Fellows. As an advocate, leaders in our community were asked to support a specific fellow, offering guidance, support, and feedback to their fellow, all in service of moving transformational research ideas forward. Prior to the pitch event, the whitepapers were shared with each advocate and University leadership.

The relationship between the advocate and fellow was not prescribed, but rather, developed naturally. For example, one advocate-fellow pair developed into a micro-writing community, where the advocate offers critical feedback to support the Fellow in sharing their research more broadly across disciplines and fields. Another advocate-Fellow pair expanded the network of the Fellow, allowing the Fellow to delve into a space that was previously unavailable to them. Another advocate voiced great skepticism after reading their assigned Fellow's white paper; however, the advocate reconsidered after witnessing the Fellow's pitch. The conversation continued outside of the pitch event and progress is being made to move the transformational research idea forward. These opportunities were made possible by developing effective matches between advocates and fellows based on needs, availability, capacity, and compatibility.

\section{PoST-FELLOWSHIP ASSESSMENT}

At the completion of the ASSERT fellowship year, fellows were again interviewed individually by the PI and co-PI. In addition, information was gathered from the University Office of Sponsored Programs regarding their grant activity. The fellows also submitted a new NSF 
conflict of interest forms, and shared updated curriculum vitae. The time-stamped pre- and postassessments have been collected. Comparative analysis indicates that ASSERT fellows submitted more grants, requested more funding, and were awarded more grants and funding (Table 1) and self-reported more research collaborators (Table 2). Three additional patents were made. In 2017, fellows published 20 publications. In 2018, 19 were published and an additional 19 were either in press or under review. Furthermore, a greater sense of community was developed between ASSERT Fellows as shown by an increase in ASSERT collaborators identified in the conflict of interest forms submitted by fellows (Table 2).

Table 1. Shifts in Grantsmanship and Funding of ASSERT Fellows

\begin{tabular}{|l|c|c|}
\hline & $\begin{array}{c}\text { Pre-ASSERT } \\
\text { Fellowship }\end{array}$ & $\begin{array}{c}\text { Post-ASSERT } \\
\text { Fellowship }\end{array}$ \\
\hline Proposals Submitted & 56 & 68 \\
\hline Funding Requested by Submitted Proposals & $\$ 32,792,277$ & $\$ 36,042,663$ \\
\hline Awarded Proposals & 17 & 20 \\
\hline \multicolumn{1}{|c|}{$\begin{array}{l}\text { Awarded Proposals } \\
\text { excluding no-cost extensions }\end{array}$} & 12 & 18 \\
\hline $\begin{array}{l}\text { Total Funding Awarded } \\
\text { Unique Funding Agencies } \\
\text { (Originating Sponsor) }\end{array}$ & $\$ 3,178,686$ & $\$ 10,917,037$ \\
\hline
\end{tabular}

Table 2. Shifts in Self-Reported Collaboration of ASSERT Fellows

\begin{tabular}{|l|c|c|} 
& $\begin{array}{c}\text { Pre-ASSERT } \\
\text { Fellowship }\end{array}$ & $\begin{array}{c}\text { Post-ASSERT } \\
\text { Fellowship }\end{array}$ \\
\hline Self-Reported Collaborators & 255 & 272 \\
\hline Self-Reported ASSERT Collaborators & 1 & 7 \\
\hline
\end{tabular}

\section{Lessons Learned}

There are several overarching lessons that we have learned from the program last year that we are using to improve the third fellowship cohort this academic year.

\section{LESSON 1: GIVERS TAKE ALL}

In business, it is common to hear the expression "winners take all." Our experiences in academia indicate that an alternative is true for faculty learning communities-where givers take all. Faculty who brought their full selves to ASSERT, both gave and received the most from the community. For those who came to share, listen, and learn, the natural give and take that happens between groups of people was highly relational in style. In comparison, those who accounted for their time, energy, and ideas in hopes of maximizing their gains and minimizing their contributions, benefited little if at all from the faculty learning community. This observation has changed our thinking when recruiting and selecting faculty to participate in ASSERT. Regardless of their career status or disciplinary lens, important questions to ask center around the faculty's desire to learn, share, and give. In response, we now explicitly ask applicants to share what they 
want to get out of ASSERT and what they want to give to ASSERT; reinforcing these questions in the application process, initial interviews, and information meetings. This lesson underpins most of the other lessons listed below.

\section{LESSON 2: SCHEDULING IS A BEAR}

We made a near fatal flaw at the onset of ASSERT. We asked the faculty when they would be available to participate in our second and third off-campus retreats after they were already accepted as Fellows. In addition to faculty being universally busy, select faculty were reluctant to prioritize the off-campus retreat without knowing the value it would provide. Reasons included sporting events, family obligations, and work deadlines. The result is that we canceled the second and third retreats - to the detriment of the group being able to truly build a sense of community, and eventually in support of the faculty that later learned the implications of this decision. In response, our facilitation became more consultancy-based-providing individual support to faculty who reached out. Those who took advantage of the mentorship ended up receiving more positive outcomes when compared to their peers. In the end, nearly every fellow communicated their desire to have the retreats, some of whom took ownership of their inflexibility. In response, we now require faculty to be available for all of the off-campus retreats and commit to attending the off-campus retreats prior to accepting the fellowship. Those who initially indicated that they were available, but ultimately found that they were not available, have been asked to reapply in the future.

\section{LESSON 3: FACULTY ARE ISOLATED IN THEIR RESEARCH LIVES ON CAMPUS}

At the onset of ASSERT, it became abundantly clear that the Fellows, regardless of their career status, research activity, or academic home, felt isolated at Boise State. Research-inactive or emerging faculty felt that the institution's increasing commitment to research was leaving them behind-many of whom were toiling to learn how to perform research in academic environments that were ill-equipped to support them. In comparison, research-intensive faculty felt isolated from the campus community in part because of their success. The demand on their time to keep their engine fed and the real or perceived lack of infrastructure for them to achieve their goals was palpable in select cases. For some faculty, this cultivated a feeling of not belonging and for others it afforded the onset of a sense of entitlement. In response, we openly engaged the topic of isolation with the faculty cohort and in doing so helped the majority see that they are not alone in their thinking nor their feelings. As with many things, once people realize that other people think and feel the way they do, the real and perceived feelings of isolation and not belonging dissipate. Ultimately, the faculty that did not want to feel isolated ended up connected with other Fellows to create a support structure focused on their scholarship or common interests while others overlooked both the opportunity and their responsibility to connect and hence became further isolated during the fellowship period. In response, we now pay closer attention the ability and willingness of faculty to take advantage of ASSERT as a faculty learning community.

\section{LESSON 4: IT IS BEST TO APPROACH THIS KIND OF WORK FROM BOTTOM UP AND TOP DOWN}

Organizational change - whether top down or bottom up - is often slow in academia and risks creating distrust in the system. In an attempt to address select cultural and structural challenges at Boise State, in an efficient and effective manner, we engaged the academic organizational structure "top" (i.e. provost and academic deans) and "bottom" (i.e. faculty) of Boise State and in doing so helped both levels acquire common language, gain similar insights, and build 
equivalent experiences in preparation for meeting in the middle. While this methodology is still being piloted, it is best described with an example.

At the onset of ASSERT, it became clear that the majority of the Fellows were not sophisticated in their understanding of scholarship and in response did not have the necessary tools to advocate for their ideas and/or methodologies. Upon further investigation, it also became clear that our tenure and promotion guidelines varied significantly from one academic unit to another; some valuing the quantity of work at the expense of quality, and others valuing grants received over the impact of the scholarship. This structural variability was reflected also by the thought variance among our senior leadership. The consequence was friction, misinformation, and frustration at many levels of the university. In response, we read and then discussed Ernest Boyer's model of scholarship [5] — the scholarships of discovery, application, integration, and teaching - with each group (i.e. organizational "top" and organizational "bottom") individually. Outcomes to date include more open conversations about what it means to be scholar at Boise State, updates to existing tenure and promotion guidelines, and greater empathy for seeing and understanding scholarship from a perspective that is not limited by our own training biases. In light of the many institutional leadership transitions at Boise State, the best outcome is that our academic deans and faculty are much more equipped and more vocal about what they want to see in the future.

LESSON 5: TO SUSTAIN ASSERT, IT MUST BE WOVEN INTO EXISTING UNIVERSITY STRUCTURES Given that grant funding is fleeting, it is imperative that we take these lessons learned and the data of program impact and now integrate this kind of faculty support into existing programs and infrastructure across the university. To this end, we are getting ready to embark on the first offcampus retreat with our new cohort and we have invited the Interim VP for Research and Economic Development and the Assistant Provost for Academic Leadership and Faculty Affairs to participate with us and to help us to consider how to sustain this effort in the future.

\section{Conclusion}

We are piloting a Center for Transformative Research at Boise State University. The vision of our Center is to build and sustain an ASSERTive community of faculty-who Align Stakeholders and Structures to Enable Research Transformation (ASSERT). Prior to joining ASSERT, faculty fellows completed a survey and individual structured interviews to assess the risk inhibitors that prevented them from germinating and then moving bold ideas forward. In response, a set of custom workshops and an off-site retreat were designed to address the specific needs of the faculty. At the end of the year, the faculty pitched their ideas to university and community leadership; which included an advocate for each of the faculty to help connect their ideas to additional resources. Lessons learned are outlined above and included: (1) faculty that gave the most to ASSERT, benefited the most from ASSERT, (2) scheduling should not be negotiated with the faculty during the fellowship period but rather become a requirement to participate in the program, (3) many faculty feel isolated in their research lives and lack a sense of belonging, (4) institutional change is most effective when working at the top and the bottom of the organization at the same time, and (5) programmatic sustainability necessitates leveraging existing university structures. When considered together, the Center for Transformative Research is analogous to national Centers for Teaching \& Learning in that it cultivates faculty learning 
communities, provides coaching and mentorship, and when executed well, can serve as the catalyst for institutional and faculty change. Rather than being a template for other institutions to follow, our pilot study serves as a modular framework for other institutions to consider. No different than the faculty we work with, institutions do their best work when they support the people they serve.

\section{References}

[1] K. J. Gillespie and D. L. Robertson, A Guide to Faculty Development, Second Edition. San Francisco, CA: Jossey-Bass, 2010.

[2] National Organization for Research Development Professionals. (n.d.) http://www.nordp.org/ [Accessed June 1, 2017].

[3] A. Kezar and S. Gehrke "Communities of Transformation and their work scaling STEM reform.” Pullias Center for Higher Education, Rossier School of Education, University of Southern California, 2015. Available:

https://pullias.usc.edu/download/communities-of-transformation-and-their-work-scalingstem-reform/ [Accessed Feb. 4, 2019]

[4] Stanford University D. School, "The inspiration walk.” Available: https://dschool.stanford.edu/resources/the-inspiration-walk. [Accessed Feb. 4, 2019]

[5] E. L. Boyer. Scholarship Reconsidered: Priorities of the Professorate. Princeton, NJ: Carnegie Foundation for the Advancement of Teaching, 1997.

[6] C. Looney, S. Donnovan, M. O’Rourke, S. Crowley, S. D. Eigenbrode, L. Rotschy, N. A. Bosque-Perez and J. D. Wulfhorst, "Seeing through the eyes of collaborators: Using toolbox workshops to enhance cross-disciplinary communication," in Enhancing Communication and Collaboration in Interdisciplinary Research, M. O'Rourke, S. Crowley, S. D. Eigenbrode and J.D. Wulfhorst, Eds. Thousand Oaks, CA: Sage Publications, 2014.

[7] J. Ziker, K. Demps, D. Nolin and M. Genuchi, “Time Allocation Workload Knowledge Study (TAWKS)" https://tawks.boisestate.edu/ [Accessed Feb. 24, 2019] 